\title{
Two cases of microlaryngeal surgery in highly obese elite vocal performers
}

Tomohiro Hasegawa ${ }^{1}$, daigo komazawa ${ }^{2}$, and yuusuke watanabe ${ }^{1}$

${ }^{1}$ International University of Health and Welfare

${ }^{2}$ AKASAKA Voice Health Center

June 28, 2021

\section{Abstract}

We describe two cases of microlaryngeal surgery under general anesthesia in severe obese elite vocal performers. Microlaryngeal surgery under general anesthesia is feasible in patients with severe obesity, provided that the anesthesiologist and nurse work together to perform preoperative simulations and take into consideration the position and anesthesia.

\section{Hosted file}

article.docx available at https://authorea.com/users/422422/articles/528141-two-cases-ofmicrolaryngeal-surgery-in-highly-obese-elite-vocal-performers

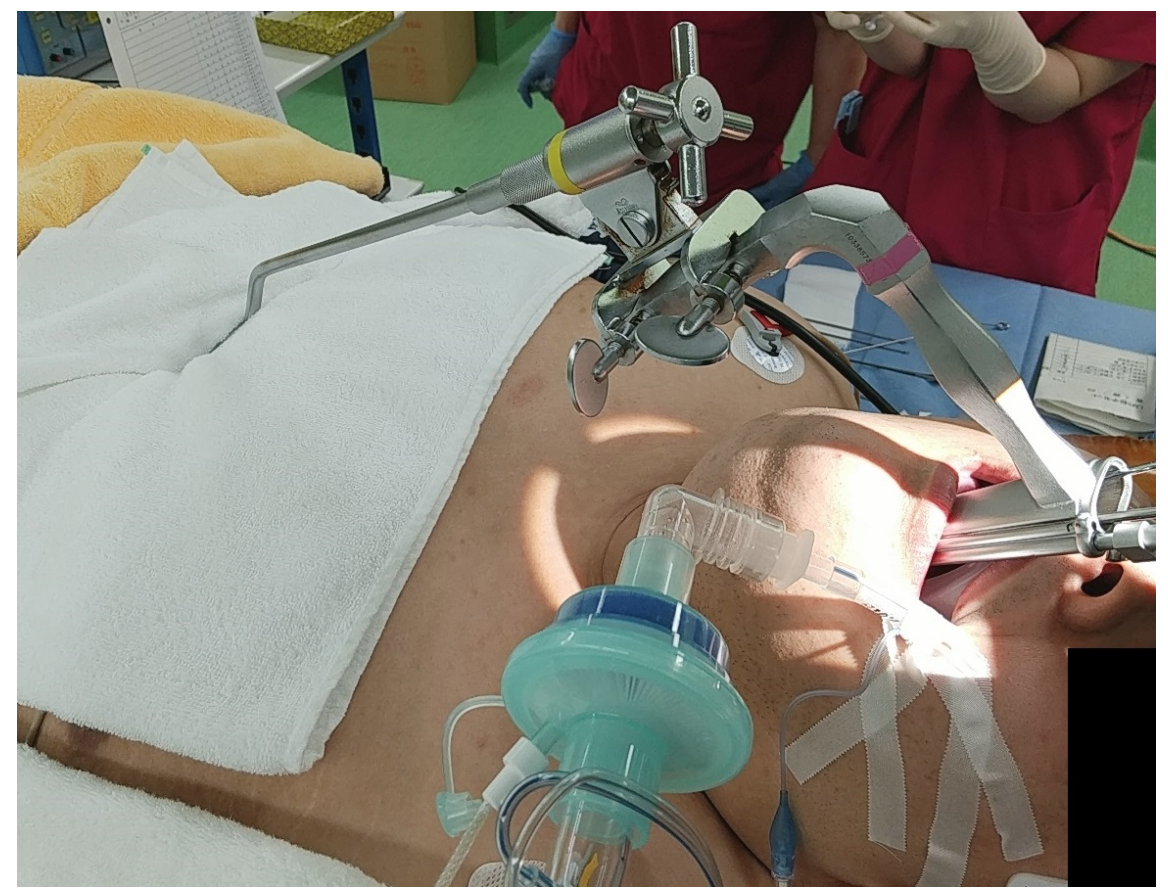



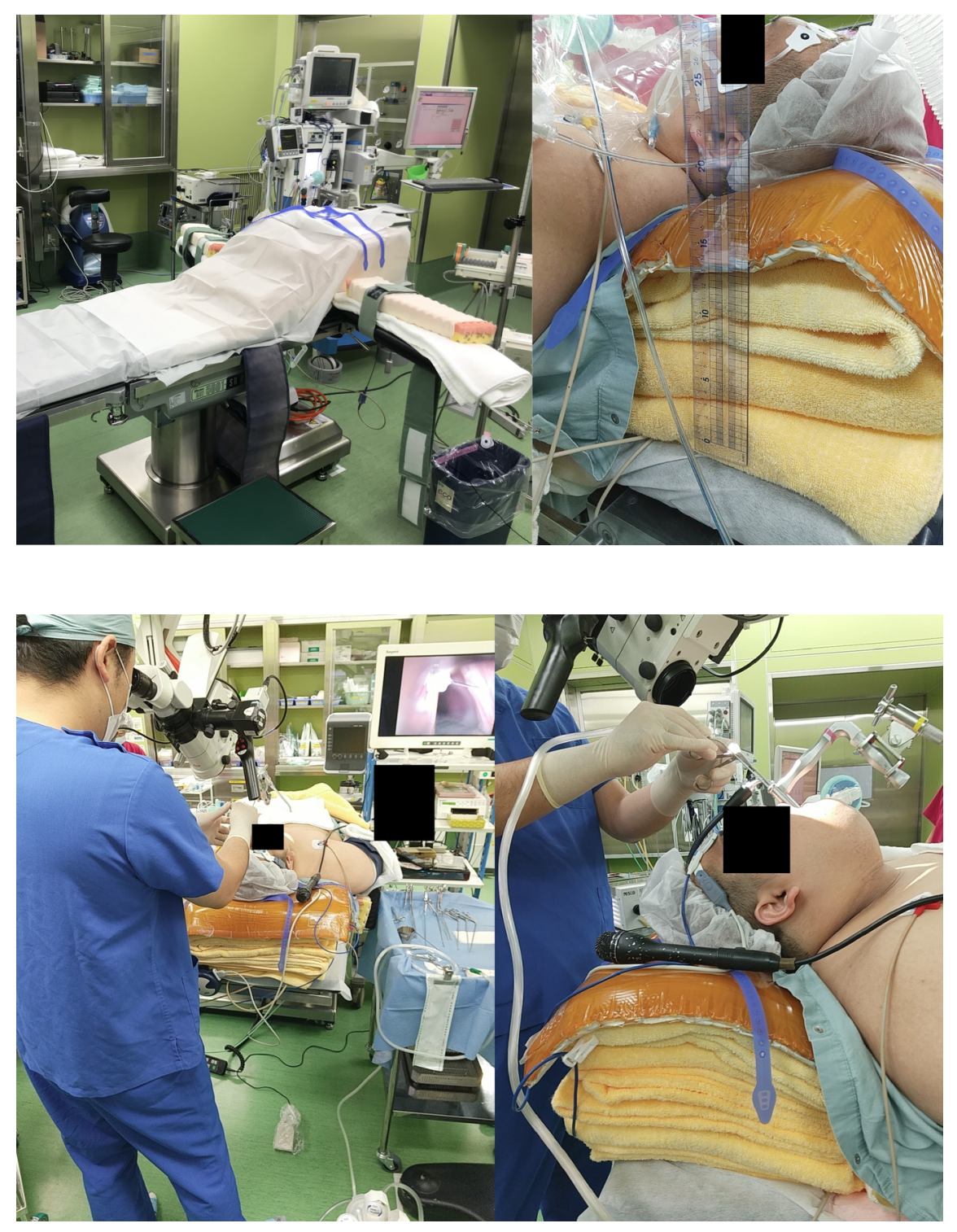


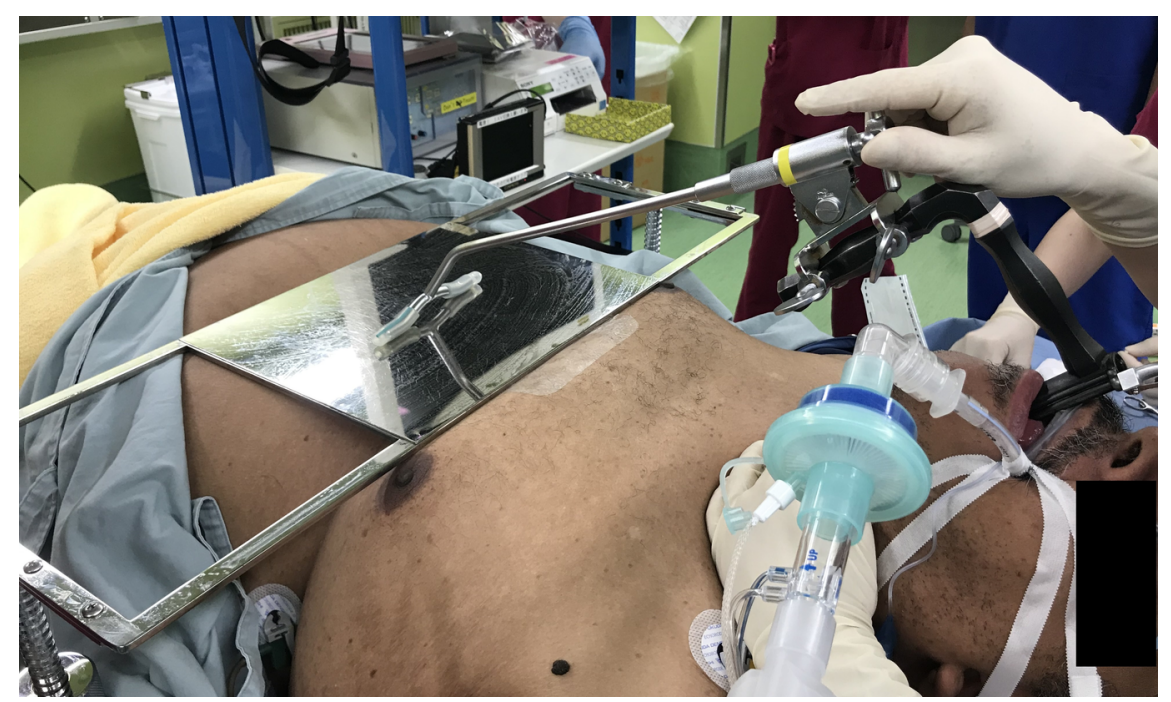

Hosted file

table.docx available at https://authorea.com/users/422422/articles/528141-two-cases-ofmicrolaryngeal-surgery-in-highly-obese-elite-vocal-performers 